Pacific Journal of Mathematics

REPRESENTATIONS OF GAUSSIAN PROCESSES BY WIENER 


\section{REPRESENTATIONS OF GAUSSIAN PROCESSES BY WIENER PROCESSES}

C. PARK

Let $\{X(t), a \leqq t \leqq b\}$ and $\{W(t), 0 \leqq t<\infty\}$ be a Gaussian process and the standard Wiener process, respectively. Investigating covariance structure of $X(t)$, the paper gives various representations of $X(t)$ in terms of $W(t)$, including stochastic integral representations. Some of these representations are useful in finding hitherto unknown barriercrossing probabilities of $X(t)$.

1. Introduction. Let $X(t)$ be a Gaussian process on some interval $I$ with covariance function

$$
R(s, t)=E\{X(s)-\mu(s)\}\{X(t)-\mu(t)\},
$$

where $\mu(t)$ is the mean function, $\mu(t)=E X(t)$.

It is well-known that a Gaussian process is uniquely determined, up to the mean function, by the covariance function $R(s, t)$.

The Gaussian process which has been studied most extensively is, of course, the Wiener process $\{W(t) ; t \geqq 0\}$. Therefore, it is natural to seek representations of Gaussian processes in terms of Wiener processes.

(i) A classical result by Doob [3, pp. 401-402] shows that: If a Gaussian process $X(t)$ has mean zero and the covariance function in the form

$$
R(s, t)=u(s) v(t), s \leqq t
$$

for $s, t$ in some interval, and if the ratio $u(t) / v(t) \equiv a(t)$ is continuous and increasing with its inverse function $a_{1}(t)$, then

$$
X\left(a_{1}(t)\right) / v\left(a_{1}(t)\right)=W(t),
$$

where $W(t)$ is the standard Wiener process (or the Brownian motion process).

Another well-known result is the following:

(ii) If a Gaussian process $X(t)$ with zero mean has a factorable covariance function on $[0, T]^{2}$, i.e.,

$$
R(s, t)=\int_{0}^{T} r(s, u) r(t, u) d u,
$$

where for each $t \in[0, T] r(t, \cdot) \in L_{2}[0, T]$, then $X(t)$ has a stochastic integral representation 


$$
X(t)=\int_{0}^{T} r(t, u) d W(u), 0 \leqq t \leqq T .
$$

(iii) More recently Berman [1, p. 32] gives stochastic integral representations of Gaussian processes with biconvex covariances:

$$
\begin{aligned}
X(t)= & \left.\sqrt{R(a, b)} Z+\int_{a}^{t} \sqrt{R_{1}(u, b}\right) d W_{1}(u)+\int_{t}^{b} \sqrt{-R_{2}(a, u)} d W_{2}(u) \\
& +\int_{a}^{t} \int_{t}^{b} \sqrt{-R_{12}(u, v)} d W(u, v) \text { for } a \leqq t \leqq b
\end{aligned}
$$

where $Z \sim N(0,1)$.

$W_{1}(t)$ and $W_{2}(t)$ are standard Wiener processes on $[a, b] W(s, t)$ is a standard Wiener process on $[a, b] \times[a, b]$ with $Z, W_{1}(t), W_{2}(t)$, and $W(s, t)$ all mutually independent. Biconvexity guarantees that the partial derivatives satisfy: $R(a, b) \geqq 0, \quad R_{1}(u, b) \geqq 0,-R_{2}(a, u) \geqq 0$, $-R_{12}(u, v) \geqq 0$ on respective domain.

By definition a covariance function $R(s, t)$ is symmetric. It is also nonnegative definite, for

$$
\begin{gathered}
\sum_{j=1}^{n} \sum_{i=1}^{n} x_{i} R\left(s_{i}, t_{j}\right) x_{j}=\sum_{j=1}^{n} \sum_{i=1}^{n} x_{i} E\left[X\left(s_{i}\right)-\mu\left(s_{i}\right)\right]\left[X\left(t_{j}\right)-\mu\left(t_{j}\right)\right] x_{j} \\
=\left\{\sum_{i=1}^{n} x_{i} E\left[X\left(s_{i}\right)-\mu\left(s_{i}\right)\right]\right\}^{2} \geqq 0 .
\end{gathered}
$$

It is also known that for each symmetric nonnegative definite function $R(s, t)$, there exists a Gaussian process whose covariance function equals $R(s, t)$. (See Doob [2, p. 72, Theorem 3.1] for reference.)

Investigating covariance structures of Gaussian processes, the paper gives numerous representations of Gaussian processes, in terms of standard Wiener processes, including stochastic integral representations. Some of these representations are demonstrated to be useful in finding hitherto unknown barrier-crossing probabilities of some Gaussian processes.

2. Main results and proofs. In application it is often more convenient to restate the Doob's theorem in the following form:

Theorem 1 (Doob). If $X(t)$ is a Gaussian process with covariance function

$$
R(s, t)=u(s) v(t) \quad(s \leqq t)
$$

for $s, t$ in some interval, and if the ratio $u(t) / v(t)$ is nondecreasing, then

$$
X(t)=v(t) W[u(t) / v(t)]+\mu(t),
$$


where $\mu(t)$ is the mean function of $X(t)$.

The theorem follows immediately by checking the covariance function. Another version of Theorem 1 can be stated as follows:

THEOREM 2. If the covariance function of a Gaussian process $X(t)$ satisfies (2.1) and if the ratio $v(t) / u(t)$ is nonincreasing, then

$$
X(t)=u(t) W[v(t) / u(t)]+\mu(t) .
$$

While Theorems 1 and 2 are very useful, they have some drawback in assuming the monotoneness of $u(t) / v(t)$. To remedy this situation, we give the following:

THEOREM 3. If $X(t)$ is a Gaussian process with covariance function

$$
R(s, t)=u(s) v(t), u(s) / v(s) \leqq u(t) / v(t),
$$

for $s, t$ in some interval, then

$$
\begin{aligned}
X(t) & =v(t) W[u(t) / v(t)]+\mu(t) \\
& =u(t) W[v(t) / u(t)]+\mu(t) .
\end{aligned}
$$

Proof. Since $R(s, t)$ is symmetric, the condition (2.2) is equivalent to:

$$
\begin{aligned}
R(s, t) & =u(s) v(t), u(s) / v(s) \leqq u(t) / v(t) \\
& =u(t) v(s), u(s) / v(s)>u(t) / v(t)
\end{aligned}
$$

Now

$$
\begin{aligned}
& E\{v(s) W[u(s) / v(s)] v(t) W[u(t) / v(t)]\} \\
& =v(s) v(t) \min \{u(s) / v(s), u(t) / v(t)\},
\end{aligned}
$$

which agrees with the $R(s, t)$. The second expression of $X(t)$ gives rise to the same covariance function.

It should be noted that if $u(t)$ or $v(t)$ vanishes at some point $t_{0}$, then $R\left(t_{0}, t_{0}\right)=E\left[X\left(t_{0}\right)-\mu\left(t_{0}\right)\right]^{2}=0$. Thus $X\left(t_{0}\right)=\mu\left(t_{0}\right)$ with probability one. Hence we regard $v\left(t_{0}\right) W\left[u\left(t_{0}\right) / v\left(t_{0}\right)\right]=u\left(t_{0}\right) W\left[v\left(t_{0}\right) / u\left(t_{0}\right)\right]=0$.

THEOREM 4. Let $X(t)$ be a Gaussian process with covariance function

$$
R(s, t)=\sum_{1}^{\infty} u_{k}^{*}(s) v_{k}^{*}(t)
$$

where 


$$
\begin{aligned}
u_{k}^{*}(s) v_{k}^{*}(t) & =u_{k}(s) v_{k}(t), u_{k}(s) / v_{k}(s) \leqq u_{k}(t) / v_{k}(t) \\
& =u_{k}(t) v_{k}(s), u_{k}(s) / v_{k}(s)>u_{k}(t) / v_{k}(t)
\end{aligned}
$$

for each $k=1,2, \cdots$. Then

$$
\begin{aligned}
X(t) & =\sum_{1}^{\infty} v_{k}(t) W_{k}\left[u_{k}(t) / v_{k}(t)\right]+\mu(t) \\
& =\sum_{1}^{\infty} u_{k}(t) W_{k}\left[v_{k}(t) / u_{k}(t)\right]+\mu(t),
\end{aligned}
$$

where $\left\{W_{k}(t)\right\}$ is a sequence of independent standard Brownian motion processes.

Proof. First of all, let us establish the $L_{2}$-convergence of the series $\sum_{1}^{\infty} v_{k}(t) W_{k}\left[u_{k}(t) / v_{k}(t)\right]$ with respect to the probability measure:

$$
\begin{aligned}
& E\left\{\sum_{m}^{n} v_{k}(t) W_{k}\left[u_{k}(t) / v_{k}(t)\right]\right\}^{2} \\
& =\sum_{m}^{n} v_{k}^{2}(t) u_{k}(t) / v_{k}(t)=\sum_{m}^{n} u_{k}(t) v_{k}(t)
\end{aligned}
$$

which converges to 0 pointwise as $m, n \rightarrow \infty$. Therefore,

$$
\begin{gathered}
E\left\{\sum_{1}^{\infty} v_{j}(s) W_{j}\left[u_{j}(s) / v_{j}(s)\right]\right\}\left\{\sum_{1}^{\infty} v_{k}(t) W_{k}\left[u_{k}(t) / v_{k}(t)\right]\right\} \\
=\sum_{1}^{\infty} v_{k}(s) v_{k}(t) \min \left\{u_{k}(s) / v_{k}(s), u_{k}(t) / v_{k}(t)\right\} \\
=\sum_{1}^{\infty} u_{k}^{*}(s) v_{k}^{*}(t)=R(s, t) .
\end{gathered}
$$

Similarly the second expression of $X(t)$ also holds.

CoROLlaRY 4.1. Let $X(t)$ be a Gaussian process with covariance function

$$
R(s, t)=\sum_{1}^{n} u_{k}^{*}(s) v_{k}^{*}(t),
$$

with $\left\{u_{k}(s)\right\}$ and $\left\{v_{k}(s)\right\}$ satisfying the same conditions in Theorem 4 for $k=1,2, \cdots, n$. Then

$$
\begin{aligned}
X(t) & =\sum_{1}^{n} v_{k}(t) W_{k}\left[u_{k}(t) / v_{k}(t)\right]+\mu(t) \\
& =\sum_{1}^{n} u_{k}(t) W_{k}\left[v_{k}(t) / u_{k}(t)\right]+\mu(t) .
\end{aligned}
$$

CoRollaRY 4.2. Let $X(t)$ be a Gaussian process with covariance function 


$$
R(s, t)=\sum_{1}^{\infty} \lambda_{k} u_{k}(s) u_{k}(t), \lambda_{k} \geqq 0 \quad(k=1,2, \cdots) .
$$

Then

$$
X(t)=\sum_{1}^{\infty} \sqrt{\lambda_{k}} u_{k}(t) W_{k}(1)+\mu(t)
$$

THEOREM 5. Let a Gaussian process $\{X(t), 0 \leqq t \leqq T\}$ have a square integrable covariance function $R(s, t)$ on $[0, T]^{2}$, and let $R(s, t)=$ l.i.m. ${ }_{n \rightarrow \infty} \sum_{1}^{n} \lambda_{k} \phi_{k}(s) \phi_{k}(t)$ be the Mercer's expansion (see [12]) with $\sum_{1}^{\infty} \lambda_{k} \phi_{k}^{2}(t)=R(t, t)$ on $[0, T]$. Then $X(t)$ has a stochastic integral representation

$$
X(t)=\int_{0}^{T} h(t, u) d W(u)+\mu(t) \text { a.e. on }[0, T],
$$

where

$$
h(t, s)=\sum_{k=1}^{\infty} \sqrt{\lambda_{k}} \phi_{k}(t) \phi_{k}(s)
$$

Proof. As covariance functions $R(s, t)$ are always nonnegative definite, the eigenvalues $\lambda_{k}$ of $R(s, t)$ are nonnegative. Observe now that

$$
\begin{gathered}
E\left[\sum_{1}^{\infty} \sqrt{\lambda_{k}} \phi_{k}(s) W_{k}(1)\right]\left[\sum_{1}^{\infty} \sqrt{\lambda_{k}} \phi_{k}(t) W_{k}(1)\right] \\
=\sum_{1}^{\infty} \lambda_{k} \phi_{k}(s) \phi_{k}(t)
\end{gathered}
$$

which converges in the mean to $R(s, t)$, we conclude that

$$
X(t)=\sum_{1}^{\infty} \sqrt{\lambda_{k}} \phi_{k}(t) W_{k}(1)+\mu(t) \text { a.e. on }[0, T] \text {. }
$$

Since the $\phi_{k}(t)$ are eigenfunctions of $R(s, t)$, they are orthonormal on $[0, T]$. Therefore, we may write

$$
W_{k}(1)=\int_{0}^{T} \phi_{k}(s) d W(s), k=1,2, \cdots .
$$

Therefore, (2.3) may be rewritten as

$$
X(t)=\sum_{1}^{\infty} \sqrt{\lambda_{k}} \phi_{k}(t) \int_{0}^{T} \phi_{k}(s) d W(s)+\mu(t)
$$

But the last expression, other than $\mu(t)$, is exactly the PaleyWiener-Zygmund stochastic integral (see [6] and [7])

$$
\int_{0}^{T} h(t, u) d W(u)
$$


because $h(t, s) \equiv \sum_{1}^{\infty} \sqrt{\lambda_{k}} \phi_{k}(t) \phi_{k}(s)$ converges in $s$ in the mean-square sense on $[0, T]$.

Although Paley-Wiener-Zygmund stochastic integral and the Ito's stochastic integral are defined quite differently, they agree almost surely for functions $h(t, \cdot) \in L_{2}[0, T]$.

CoRollary 5.1. If a Gaussian process $\{X(t), 0 \leqq t \leqq T\}$ has continuous covariance function $R(s, t)$ on $[0, T]^{2}$, then

$$
X(t)=\int_{0}^{T} h(t, u) d W(u) \text { on }[0, T],
$$

where $h(t, u)$ has the same expression as in Theorem 5.

THEOREM 6. Let $\{X(t), 0 \leqq t \leqq T\}$ be a Gaussian process, and let $\mu_{X}$ and $\mu_{W}$ be the probability measures generated by $\{X(t)$, $0 \leqq t \leqq T\}$ and $\{W(t), 0 \leqq t \leqq T\}$, respectively. Then $u_{x} \sim u_{W}$ (mutually absolutely continuous) iff there exists a complete orthonormal system $\left\{\alpha_{k}(t)\right\}$ on $[0, T]$ and a positive sequence $\left\{a_{k}\right\}$ with $\sum\left(1-a_{k}\right)^{2}<\infty$ such that

$$
X(t)=\int_{0}^{T} h(t, u) d W(u)+\mu(t),
$$

where

$$
h(t, u)=\sum \sqrt{a_{k}} \alpha_{k}(u) \int_{0}^{t} \alpha_{k}(v) d v
$$

Proof. According to Shepp [12, p. 322], $\mu_{X} \sim \mu_{W}$ iff $X(t)$ has covariance function $R(s, t)=\min (s, t)-\int_{0}^{s} \int_{0}^{t} K(u, v) d v d u$ for a symmetric kernel $K(s, t) \in L_{2}[0, T]^{2}$ and the spectrum

$$
\sigma(K) \equiv\left\{\lambda: \int_{0}^{T} K(t, u) \beta(u) d u=\lambda \beta(t), \beta \in L^{2}[0, T]\right\} \subset(-\infty, 1) .
$$

Let $\sum \lambda_{k} \beta_{k}(u) \beta_{k}(v)$ be the Mercer's expansion of $K(u, v)$. Then

$$
\begin{aligned}
R(s, t) & =\min (s, t)-\int_{0}^{s} \int_{0}^{t} K(u, v) d u d v \\
& =\sum \int_{0}^{s} \int_{0}^{t} \beta_{k}(u) \beta_{k}(v) d v d u-\sum \int_{0}^{s} \int_{0}^{t} \lambda_{k} \beta_{k}(u) \beta_{k}(v) d v d u \\
& =\sum a_{k} \int_{0}^{s} \beta_{k}(u) d u \int_{0}^{t} \beta_{k}(v) d v, \quad a_{k}=1-\lambda_{k} .
\end{aligned}
$$

Hence by Corollary 4.2,

$$
X(t)=\sum \sqrt{a_{k}} \int_{0}^{t} \beta_{k}(v) d v W_{k}(1)+\mu(t) .
$$


This expression is identical to (2.3) with $\phi_{k}(t)=\int_{0}^{t} \beta_{k}(v) d v$.

$$
\therefore X(t)=\int_{0}^{t} h(t, u) d W(u)+\mu(t) \text {, }
$$

where

$$
h(t, u)=\sum \sqrt{a_{k}} \beta_{k}(u) \int_{0}^{t} \beta_{k}(v) d v .
$$

Now, since $\lambda_{k}<1$, we have $a_{k} \equiv 1-\lambda_{k}>0$, and $\sum\left(1-a_{k}\right)^{2}=$ $\sum \lambda_{k}^{2}=\int_{0}^{T} \int_{0}^{T} K(u, v)^{2} d u d v<\infty$. Thus the conditions are necessary. The converse follows by reversing the steps.

3. Examples and applications.

A. The standard Wiener process $X(t)$ has covariance function $R(s, t)=\min (s, t)$. Therefore $R(s, t)=s, s \leqq t$. Thus, by Theorem 1, $W(t)=t W(1 / t), t>0$. Now, consider the tied-down Brownian motion: $\{X(t), 0 \leqq t \leqq 1\}=\left\{W(t), 0 \leqq t \leqq 1 \mid W(1)=x_{0}\right\}$. Using the above expression, one can express:

$$
\{X(t), 0 \leqq t \leqq 1\}=\left\{t\{W(1 / t)-W(1)\}+t x_{0}, 0 \leqq t \leqq 1\right\},
$$

where we use the convention that $t W(1 / t)=0$ at $t=0$. Thus, the covariance function of $X(t)$ is $R(s, t)=s(1-t), s \leqq t$. Hence, Theorem 1 gives

$$
\begin{array}{rlrl}
X(t) & =(1-t) W\left(\frac{t}{1-t}\right)+t x_{0}, & 0 \leqq t<1 \\
& =x_{0}, & t & =1,
\end{array}
$$

while Theorem 2 gives

$$
\begin{aligned}
X(t) & =t W\left(\frac{1-t}{t}\right)+t x_{0}, & & 0<t \leqq 1, \\
& =0, & & t=0 .
\end{aligned}
$$

Other well-known representations are:

$$
X(t)=W(t)-t W(1)+t x_{0},
$$

and

$$
X(t)=W^{*}(t, 1-t)+t x_{0},
$$

where $W^{*}(s, t)$ stands for the standard two-parameter Yeh-Wiener process (see [11] and [14]). Malmquist [5] and Park and others ([8], [9], [10]) used these representations extensively to obtain their 
results.

B. The Ornstein-Uhlenbeck process $X(t)$ has covariance function $R(s, t)=\sigma^{2} \exp \{-\beta(t-s)\}$ for $s<t$ and $\beta>0$ with $\mu(t) \equiv 0$. Therefore by Theorems 1 and 2,

$$
\begin{aligned}
X(t) & =\sigma e^{-\beta t} W\left(e^{2 \beta t}\right) \\
& =\sigma e^{\beta t} W\left(e^{-2 \beta t}\right) .
\end{aligned}
$$

These representations enable us to evaluate the barrier-crossing probabilities of the type

$$
P\left\{\sup _{0 \leqq t \leqq T} X(t)-f(t) \geqq 0\right\}
$$

for sectionally continuous functions $f(t)$. (See [9] for reference.)

C. Consider the Gaussian process $\{X(t), 0 \leqq t \leqq 1\}$ with zero mean and covariance function

$$
R(s, t)=\left(-3 s^{3}+4 s^{2}\right) t \text { if }-3 s^{2}+4 s \leqq-3 t^{2}+4 t .
$$

Then by Theorem 3,

$$
X(t)=t W\left(-3 t^{2}+4 t\right), \quad 0 \leqq t \leqq 1 .
$$

Suppose we want to find the probability

$$
P_{1}=P\left\{\sup _{0 \leqq t \leqq 1} X(t)-f(t)<0\right\}
$$

for a sectionally continuous function $f(t)$ on $[0,1]$ with $f(0)>0$. Then by the representation, we get

$$
\begin{aligned}
& P_{1}= P\left\{\sup _{0 \leqq t \leqq 1} t W\left(-3 t^{2}+4 t\right)-f(t)<0\right\} \\
&= P\left\{\sup _{0<t \leq 2 / 3} W\left(-3 t^{2}+4 t\right)-\frac{1}{t} f(t)<0,\right. \\
&\left.\sup _{2 / 3 \leqq t \leqq 1} W\left(-3 t^{2}+4 t\right)-\frac{1}{t} f(t)<0\right\} \\
&= P\left\{\sup _{0<s \leqq 4 / 3} W(s)-\frac{3}{2-\sqrt{4-3 s}} f\left(\frac{2-\sqrt{4-3 s}}{3}\right)<0,\right. \\
&\left.\sup _{1 \leqq s \leqq 4 / 3} W(s)-\frac{3}{2+\sqrt{4-3 s}} f\left(\frac{2+\sqrt{4-3 s}}{3}\right)<0\right\} .
\end{aligned}
$$

Let

$$
\begin{aligned}
g(s) & =\frac{3}{2-\sqrt{4-3 s}} f\left(\frac{2-\sqrt{4-3 s}}{3}\right), \quad 0<s \leqq 1 \\
& =\min \left\{\frac{3}{2-\sqrt{4-3 s}} f\left(\frac{2-\sqrt{4-3 s}}{3}\right),\right.
\end{aligned}
$$




$$
\left.\frac{3}{2+\sqrt{4-3 s}} f\left(\frac{2+\sqrt{4-3 s}}{3}\right)\right\}, \quad 1 \leqq s \leqq \frac{4}{3} .
$$

Then

$$
P_{1}=P\left\{\sup _{0<s \leqq 4 / 3} W(s)-g(s)<0\right\} .
$$

This can be evaluated by the method in [9]. Until now we were unable to find probabilities of the type (3.1) mainly because the covariance function of $X(t)$ does not satisfy the Doob's condition in Theorem 1.

\section{REFERENCES}

1. S. M. Berman, Gaussian processes with biconvex covariances, J. Mult. Anal., 8 (1978), 30-44.

2. J. L. Doob, Stochastic Processes, J. Wiley and Sons, Inc., 1953.

3. - Heuristic approach to the Kolmogorov-Smirnov theorems, Ann. Math. Stat., 20 (1949), 393-403.

4. G. Kallianpur and $\mathrm{H}$. Oodaira, Nonanticipative representations of equivalent Gaussian processes, Ann. Prob., 1 (1973), 104-122.

5. S. Malmquist, On certain confidence contours for distribution functions, Ann. Math. Stat., 25 (1954), 523-533.

6. R. E. A. C. Paley, N. Wiener and A. Zygmund, Notes on random functions, Math. Z., 37 (1933), 647-668.

7. C. Park, A generalized Paley-Wiener-Zygmund integral and its applications, Proc. Amer. Math. Soc., 23 (1969), 388-400.

8. C. Park and S. R. Paranjape, Distribution of the supremum of the two-parameter Yeh-Wiener process on the boundary, J. Appl. Prob., 10 (1973), 875-880.

9. C. Park and F.J. Schuurmann, Evaluations of Barriercrossing probabilities of Wiener paths, J. Appl. Prob., 13 (1976), 267-275.

10. C. Park and D. L. Skoug, Wiener integrals over the sets bounded by sectionally continuous barriers, Pacific J. Math., 78 (1978), 455-466.

11. W. J. Park, A multi-parameter Gaussian process, Ann. Math. Stat., 41 (1970), $1582-1595$.

12. F. Riesz and B. Sz.-Nagy, Functional Analysis, Frederick Ungar, New York, 1955.

13. L. A. Shepp, Radon-Nikodym derivatives of Gaussian measures, Ann. Math. Stat., 37 (1966), 321-354.

14. J. Yeh, Wiener measure in a space of functions of two variables, Trans. Amer. Math. Soc., 95 (1960), 433-450.

Received February 18, 1980.

MIAMI UNIVERSITY

OXFORD, OH 45056 



\section{PACIFIC JOURNAL OF MATHEMATICS}

\section{EDITORS}

DONALD BABBITT (Managing Editor)

University of California

Los Angeles, CA 90024

Hugo RossI

University of Utah

Salt Lake City, UT 84112

C. C. MOORE and ANDREW OGG

University of California

Berkeley, CA 94720
J. DugundjI

Department of Mathematics

University of Southern California

Los Angeles, CA 90007

R. FINN and J. MILGRAM

Stanford University

Stanford, CA 94305

\section{ASSOCIATE EDITORS}
R. ARENS
E. F. BECKENBACH
B. H. NeUmanN
F. WOLF
K. YosHIDA

\section{SUPPORTING INSTITUTIONS}

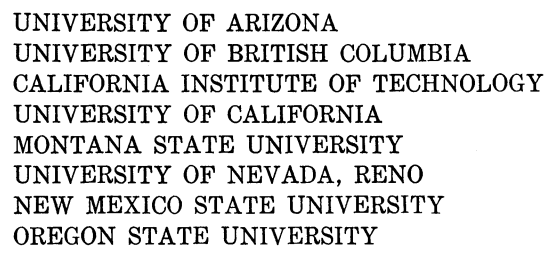

UNIVERSITY OF ARIZONA

UNIVERSITY OF BRITISH COLUMBIA CALIFORNIA INSTITUTE OF TECHNOLOGY

UNIVERSITY OF CALIFORNIA

MONTANA STATE UNIVERSITY

UNIVERSITY OF NEVADA, RENO

NEW MEXICO STATE UNIVERSITY OREGON STATE UNIVERSITY

\author{
UNIVERSITY OF OREGON \\ UNIVERSITY OF SOUTHERN CALIFORNIA \\ STANFORD UNIVERSITY \\ UNIVERSITY OF HAWAII \\ UNIVERSITY OF TOKYO \\ UNIVERSITY OF UTAH \\ WASHINGTON STATE UNIVERSITY \\ UNIVERSITY OF WASHINGTON
}

The Supporting Institutions listed above contribute to the cost of publication of this Journal, but they are not owners or publishers and have no responsibility for its content or policies.

Mathematical papers intended for publication in the Pacific Journal of Mathematics should be in typed form or offset-reproduced, (not dittoed), double spaced with large margins. Please do not use built up fractions in the text of the manuscript. However, you may use them in the displayed equations. Underline Greek letters in red, German in green, and script in blue. The first paragraph or two must be capable of being used separately as a synopsis of the entire paper. Please propose a heading for the odd numbered pages of less than 35 characters. Manuscripts, in triplicate, may be sent to any one of the editors. Please classify according to the scheme of Math. Reviews, Index to Vol. 39. Supply name and address of author to whom proofs should be sent. All other communications should be addressed to the managing editor, or Elaine Barth, University of California, Los Angeles, California, 90024.

50 reprints to each author are provided free for each article, only if page charges have been substantially paid. Additional copies may be obtained at cost in multiples of 50 .

The Pacific Journal of Mathematics is issued monthly as of January 1966. Regular subscription rate: $\$ 102.00$ a year (6 Vols., 12 issues). Special rate: $\$ 51.00$ a year to individual members of supporting institutions.

Subscriptions, orders for numbers issued in the last three calendar years, and changes of address shoud be sent to Pacific Journal of Mathematics, P.O. Box 969, Carmel Valley, CA 93924, U.S.A. Old back numbers obtainable from Kraus Per!odicals Co., Route 100, Millwood, NY 10546.

\section{PUBLISHED BY PACIFIC JOURNAL OF MATHEMATICS, A NON-PROFIT CORPORATION}

Printed at Kokusai Bunken Insatsusha (International Academic Printing Co., Ltd.). 8-8, 3-chome, Takadanobaba, Shinjuku-ku, Tokyo 160, Japan.

Copyright (C) 1981 by Pacific Jounal of Mathematics Manufactured and first issued in Japan 


\section{Pacific Journal of Mathematics}

Vol. 94, No. $2 \quad$ June, 1981

Thomas E. Armstrong and William David Sudderth, Nearly strategic

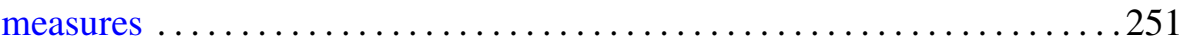

John J. Buoni, Artatrana Dash and Bhushan L. Wadhwa, Joint Browder

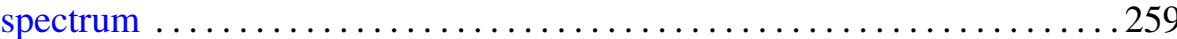

Jack Paul Diamond, Hypergeometric series with a $p$-adic variable . .......265

Raymond Frank Dickman, Jack Ray Porter and Leonard Rubin,

Completely regular absolutes and projective objects ............ 277

James Kenneth Finch, On the local spectrum and the adjoint ........... 297

Benno Fuchssteiner, An abstract disintegration theorem ............ 303

Leon Gerber, The volume cut off a simplex by a half-space $\ldots \ldots \ldots \ldots 311$

Irving Leonard Glicksberg, An application of Wermer's subharmonicity

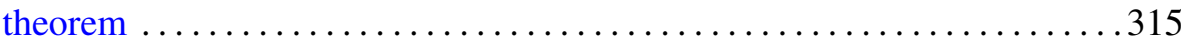

William Goldman, Two examples of affine manifolds ............... 327

Yukio Hirashita, On the Weierstrass points on open Riemann surfaces .....331

Darrell Conley Kent, A note on regular Cauchy spaces ............. 333

Abel Klein and Lawrence J. Landau, Periodic Gaussian

Osterwalder-Schrader positive processes and the two-sided Markov

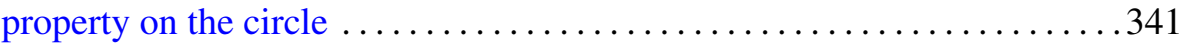

Brenda MacGibbon, $\mathscr{K}$-Borelian embeddings and images of Hausdorff

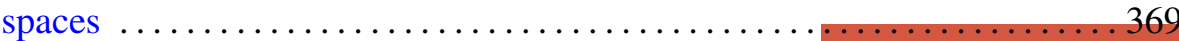

John R. Myers, Homology 3-spheres which admit no PL involutions . . . . . 379

Boon-Hua Ong, Invariant subspace lattices for a class of operators . . . . . 385

Chull Park, Representations of Gaussian processes by Wiener processes . . . 407

Lesley Millman Sibner and Robert Jules Sibner, A sub-elliptic estimate

for a class of invariantly defined elliptic systems $\ldots \ldots \ldots \ldots \ldots \ldots .417$

Justin R. Smith, Complements of codimension-two submanifolds. III.

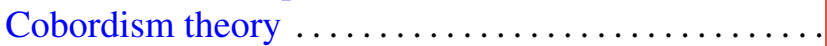

William Albert Roderick Weiss, Small Dowker spaces

David J. Winter, Cartan subalgebras of a Lie algebra and its ideals. II ... 